\title{
INTERPRETACIÓN DE DOS CULTURAS EN UN RELATO ALJAMIADO MORISCO
}

En los orígenes de los "exempla" medievales es posible encontrar tanto fuentes judeocristianas como musulmanas, y resulta innecesario demostrar el papel fecundo de esta aportación. Hemos escogido un relato aljamiado morisco que aparentemente no tiene otro punto de partida que el Corán-citado en árabe y traducido-y los Hechos de los Apóstoles, puesto que se trata de la conversión de Pablo, pero tratada de una manera que no parece tener precedentes. Procuraremos demostrar, que si bien es musulmán en cuanto al sistema de valores que preconiza', el relato está lleno de elementos del fondo medieval hispánico común, lo que hacía posible cierto intento de diálogo entre moriscos y cristianos.

Destacaremos en el texto aljamiado algunos elementos culturales importantes: el rey, el ermitaño, el pueblo que vive en cavernas o cabañas y los diferentes gestos ligados a la visión de fenómenos sobrenaturales.

Trataremos de indicar hasta dónde llegan los parecidos y en dónde hay diferencias dentro de la enseñanza general que se encuentra en los relatos ejemplares, tanto árabes y moriscos como cristianos, que utilizan esos mismos elementos. Veremos que, aun cuando las doctrinas difieren, el sentido que transmiten es exactamente el mismo: sirven para rodear ciertas instancias del relato con un halo positivo o negativo para todos. Desempeñan así una función narrativa importante en el texto morisco y, sobre todo, están destinados a orientar las simpatías de los lectores. Presentaremos más adelante un cuadro de los valores que se encuentran en oposición ${ }^{2}$.

\footnotetext{
'Esta actitud no es nueva, pues se remonta a la doctrina según la cual todos los profetas recibieron la misma revelación. Véanse, por ejemplo, $\mathbf{R}$. BASSET, Mille et un contes, récits et légendes a rabes, París, 1924-1927, t. 3, núm. 115 en donde Jesús hace profesión de fe islámica; y F. GUILLEN ROBLES, Leyendas moriscas sacadas de varios manuscritos, Madrid, 1886, t. l, en donde se hallan textos relacionados con Job, Salomón, Moisés.

${ }^{2}$ Los principios de semiología que utilizo provienen de A. J. GREIMAS, Du sense, París. 1970, y del Groupes D'ENTREVERnes, Analyse sémiotique des textes, Lyon, 1978. He creído encontrar en ellos un posible sistema de comparación de textos, más refinado que el de U. PROPP, Morphologie du conte, Paris, 1970. No daré detalles de los diferentes análisis, sino solamente los resultados que, en mi opinión, interesan al relato del que me ocupo.
} 
Para mayor comodidad, presentamos un breve resumen del texto al que daremos el título de "Pablo y los creyentes"'.

Jesús, hijo de María, forma sesenta discípulos, quienes, a su vez, convencen a alrededor de setecientos hombres a que los sigan, y después Jesús es transportado al cielo, según el Corán. Pablo, en ese entonces rey de los judíos, los extermina. Los que han podido escapar huyen a los confines de la "Tierra Santa". Pablo aún les teme, pues sabe que sus enseñanazas serán adoptadas por todos ("bi "én aína $k^{c}$ reyerán las jemes" fol. $37 \mathrm{r}$ ). Entonces se viste como ellos y se incorpora a su seno. Se hace aceptar su conversión: Jesús le quitó temporalmente la vista y los otros sentidos para hacerle comprender que debía unirse a sus antiguas víctimas y adoptar su fe. Los discípulos aceptan que se quede y enseñe. Por petición suya le hacen con ceniza un lugar para dormir, y en un principio todo transcurre sin problemas. Un día no sale a impartir sus enseñanzas habituales y todos temen que haya tenido una visión desfavorable. Finalmente les abre y responde a sus preguntas: "No-vi kosa nenguna mala mas yo ob un aku" erdo, i dezirvos lo e, i se veredes ke será bu weno, tomadlo; sino, tornadme d-ello" (fol. $38 \mathrm{v}$ ). Al final de la discusión cambian su orientación durante la plegaria. Se mantiene encerrado por segunda vez, y a la pregunta "¿as visto...?" responde: "No, Mas e visto un aku "erdo" (fol. 39r). Esta vez comen alimentos prohibidos. Se encierra por tercera vez y dice: "Lo ke yo e visto..." (fol. 39v). Se trata de creer que Jesús es Dios. Yac qüb y Nastur aceptan, así como Malqun, quien incluso agrega a esto que Dios es una Trinidad. Únicamente el Creyente (el Mūmin) rehúsa y huye con los suyos ("sus amigos i pariy entes" fol. 40v). Pablo y los adeptos de la nueva fe los persiguen para matarlos; los fugitivos se refugian entre lo judíos, quienes en un principio los capturan y después los dejan vivir a su manera en cavernas y ermitas cercanas a las montañas ("Las ku wevas i las ermitas semejante a las montañas", fol. 4lr) se cita la azora núm. 57 del Corán (fin del versículo 27) para infamar a aquellos que agregan a su religión preceptos que Dios no desea, aclarando que lo que hicieron el Creyente y los suyos (la vida de ermitaños), aunque no lo pidió Dios directamente, merece una recompensa, porque ellos poseen " $g$ raçi a i misalikordi a $i$-umillança”" (fol. 4lv). A partir de que Mahoma se les manifiesta, se vuelven musulmanes.

De más está decir que el ermitaño, tanto para cristianos como para musulmanes, es un sujeto ejemplar, con la sola excepción de un caso, el de la "tentación del ermitaño"4. Desde el lado cristiano se salva in extremis. Si los relatos árabes y moriscos lo precipitan en el infierno, es porque está en juego otro tema: se trata de ilustrar un pasaje del Corán donde se dice que el diablo traiciona al hombre, y 
de ahí aprovechar para insistir en que hasta el demonio está someti. do a Dios ${ }^{5}$. Bajo la apariencia de una joven, el diablo tienta y compromete a un ermitaño, y luego le dice que si lo adora, lo liberará de esa falta. El ermitaño obedece, pero el diablo lo abandona, y los padres de la joven matan al ermitaño cuando se encuentra en doble estado de pecado. La treta del diablo parece aún más temible puesto que ha vencido a quien de ordinario se le resiste. Es una manera de decir que es necesario acudir a Dios y no contar con las propias fuerzas, problema que volveremos a encontrar más adelante. Lo anterior no menoscaba la reputación de santidad del ermitaño.

Entre los relatos ejemplares existen algunos en donde se encuentran reunidos varios de los elementos que estamos buscando; ellos nos permitirán estudiar algunas oposiciones instructivas. La Edad Media colocó con frecuencia frente a frente el extremo poder y la extrema indigencia. Trataremos de ver lo que encubre a través de los siguientes temas: el rey (o el príncipe) que se hace ermitaño, y también el rey que encuentra a un filósofo, lo que no nos apartará de nuestro propósito, puesto que sirve de introducción a un tercer tema, el del rey que encuentra a un pueblo de filósofos (o a un pueblo virtuoso).

Los textos musulmanes son los que más hincapié hacen en las razones que llevan a un rey o a un príncipe a dejarlo todo y convertirse en un hombre santo que reza, hace penitencia y se dedica a los trabajos manuales más rudos. Varios relaios de este tipo ilustran el primer capítulo de la célebre Lámpara de los príncipes, escrita -aparente paradoja- para preparar al príncipe a subir al trono ${ }^{6}$. Señalemos como el más ejemplar de los textos la versión morisca de la vida de Salomón: ésta nos hace llegar al fondo del problema al mostrarnos en la actitud de Salomón un paralelo absoluto con la de Job, arquetipo del despojado tanto entre cristianos como entre musulmanes?. Salomón pierde su poder extraordinario, don de Dios, sin haber cometido falta alguna; no impugna el fundamento de lo que le acontece y se retira a hacer penitencia; se convierte en el más pobre de los pobres, reza, ayuna y trabaja. Como Job, jamás pide que se le restituya su estado anterior, sino tan sólo pide el perdón de Dios.

Si examinamos el problema narrativo que esto plantea, vemos que es el del "destinador", el que "hace actuar". En apariencia, este

5 A. González Palencia, Historias y leyendas. Estudios literarios. Madrid, 1942. pp. $79 \mathrm{ss}$.

${ }^{6}$ AL TORTUkI, Lámpara de los principes, trad., de M. Alarcón. Madrid, 1930, t. 1, p. 26, historia de Imrulcáis; p. 68 que trata de la hija de un rey; pp. 22 ss., Ibrahim renuncia a ochenta tronos para convertirse en pastor: F. Guillén Robles, op, cit., t. 1, pp. 281-311; en R. Basset, op. cit., t. 3, pp. 153-157, la historia de Salomón,

${ }^{7}$ F. GUILLÉN ROBLES, op. cit., $t .1$, pp. 225 ss. 
papel corresponde al rey - ya que él decide partir por sí sóloprograma del que, al mismo tiempo, es ejecutante, ¿Qué hay de eso en realidad? ¿Cuáles son los criterios que lo hicieron decidirse, quién juzga el valor que entrañan? Sobre esto, se remite a Dios. En el plano narrativo ello significa que el Destinador que impone en el relato cierto sistema de valores no siempre es al mismo tiempo, según Greimas, el "destinador epistémico", el que sabe si en verdad son los valores buenos, y por qué. Dios posee siempre ese papel último, y Salomón unicamente decide y actúa para conformarse al programa de Dios, sin saber si podrá lograrlo algún día. A continuación, después de que se le devuelven sus riquezas y poder, Dios no hace más que proporcionar una información, revelar que Salomón ha alcanzado efectivamente los verdaderos valores (hacerlo ir al Paraíso hubiera tenido el mismo efecto). Poco importa que un príncipe deje o no el trono, siempre que reconozca que sólo Dios conoce los verdaderos valores, dicho de otro modo, que ostente la sumisión perfecta. Así, en otro texto, el consejero de Imrulcáis le da a escoger: "o mantenerte en cuanto hagas dentro de la obediencia al Señor, o vestirte un cilicio y retirarte a un monte para consagrarte allí al servicio de Dios" 8 . El problema narrativo se plantea en los mismos términos en los relatos cristianos, salvo un matiz, que trataremos de apreciar.

El relato de Barlaam y Josafat, que probablemente proviene de la India, es el que más se conforma a lo que acabamos de ver; en otros se antepone la suerte de los súbditos de rey y se dice que éste debe encontrar un sucesor justo ${ }^{9}$. Al parecer, el caso es tan común en el universo mental de la época, que ya no se le menciona sino en cuanto referencia, como sucede en el Conde Lucanor, por ejemplo, donde el rey finge hacerse ermitaño para saber si su consejero es desinteresado o no ${ }^{10}$. Acabamos de ver que el rey debe, ante todo, preocuparse por sus súbditos y principalmente por los pobres. Aunque el Islam predica también la limosna, es aquí donde se expresa la originalidad de los textos cristianos. Tenemos el "exemplum" en el que un rey se prosterna delante de los más miserables, a quienes llama, para justificar su gesto, "pregoneros de mi señor Dios"'l, en un gesto que recuerda el beso de San Francisco de Asís al leproso, y que es una clara alusión al dogma de la Encarnación. En el plano narrativo, los pobres son portadores de la palabra del "Destinador", único juez de los valores, en tanto que en ios relatos musulmanes Dios se hace oír por sí mismo.

${ }^{8}$ AL TORTUXI, op. cit., t. l, p. 26.

${ }^{9}$ Castigos e documentos del Rey don Sancho, BAE, t. 51, p. 64, donde un joven príncipe renuncia al trono, pero por seis méritos consigue otro; Libro de los exenplos, por A.B.C., por Sánchez de Vercial, ed. crítica de J. E. Keller, Madrid, 1961, núm. 22.

${ }^{10}$ DON JUAN MANUEL, El conde Lucanor, Ex. núm. 1; Libro de los exenplos, núm. 75 (4), y núm. (215).

${ }^{11}$ Ibid., núm. 192 (121). 
Junto a este primer tema está el de la soberanía humana puesta en jaque por la muerte: el hombre comprende entonces que su poder no es el valor supremo. La idea de Dios no aparece obligatoriamente, pero la dimensión moral del problema está en primer plano. Citemos "Jesús y la calavera", donde la calavera abandonada revela que era la de un rey ${ }^{12}$; la oración fúnebre de Alejandro ${ }^{13}$, y sobre todo el encuentro con el filósofo ${ }^{14}$. La Disciplina clericalis presenta el texto más sobrecogedor. El filósofo piojoso dice brutalmente a los sirvientes del rey: "Vuestro señor no es el mío, sino más bien mi criado", queriendo decir con esto que el rey es esclavo de sus voluntades en tanto que el filósofo domina la suya. Desde el punto de vista narrativo las palabras del filósofo no son absolutamente exactas: es cierto que acumula los dos papeles del 'Destinador" del que hemos hablado, pero solamente con relación a sí mismo; con relación a los otros, y en consecuencia al rey, únicamente revela los valores verdaderos. Más aún, puesto que se "hace actuar" a sí mismo, no hace sino evitar la ambición, y entonces el alcance de su acción se nos muestra como negativo.

El problema es prácticamente el mismo en el caso del pueblo de ascetas con que se encuentra Alejandro: éstos viven "en las cuevas de las montañas" y desprecian las vanidades del mundo, sin buscar dominarse entre $\mathbf{s i}^{15}$. Otros, cristianizados en el Libro de los Exenplos $^{16}$, pobres al extremo pero siempre habitados por la dicha, son sorprendidos un día por un rey "en una morada de cueva"; su felicidad, señala el texto, proviene de lo que ellos conocen como "el reyno que dura sienpre"'17; ellos conocen los verdaderos valores.

Para el relato que nos ocupa resulta importante hablar también de las visiones. Limitémonos a las que tienen como beneficiario a un santo o a un ermitaño: a menudo tienen por efecto justificar la calificación de Dios como revelador de los valores verdaderos, de donde se explica que encontremos en el paraíso a personajes inespe$\operatorname{rados}^{18}$.

${ }^{12}$ R. BASSET, op, cit., t. 3 núm. 110, que se encuentra también en G. GUILLEN ROBLES, op. cit., t. 1, pp. 129-170.

13 Libro de los exenplos, ed. cit., núm. 294 (225).

14 Ibid., núm. 259 (190), y especialmente núm. 427 (381).Disciplina clericalis, ed. y trad. de A. González Palencia, Madrid-Granada. 1948, núm. 27; cito por la traducción.

${ }^{15}$ El tema de Alejandro y los Brahamanes proviene del Pseudo Calístenes, como dice A. D. KRAPPS en su artículo "Les sources du Libro de los exenplos", $B H i, 39$ (1937), pp. 5 ss. Véanse también C. GARCIA GUAL, Seudo Callisthenes, traducción de vida y hazañas de Alejandro de Macedonia, Madrid, pp. 177-189; R. BASSET, op. cit., t, 3, núm. 90; para la narración española, Espéculo de los legos, texto inédito del siglo xv, ed. de J. M. Mohedano Hernández, Madrid, 1951, núm. 385, y especialmente Libro de los exenplos, ed. cit., núm. 6, en el que los Brahamanes llegan a ser habitantes de Bragamanos, y su jefe desea que su nombre se cristianice en el Didimo.

${ }^{16}$ R BASSET, op. cit., t. 3, núm. 329, y Libro de los exenplos, ed. cit., núm. 350 (288).

${ }^{17}$ lbid., p. 270.

${ }^{18}$ R. BASSET, op cit., t. 3, núm. 60, y F. GUILLEN DE ROBLES, op. cit., t. 1, pp. 316-322; 
Próximo a los secretos de Dios, ejemplar, el ermitaño es el personaje que uno encuentra para dar con el camino del cielo. Bástenos con mencionar el famoso ejemplo del rey Rodrigo y de la penitencia que le fue impuesta. Los esfuerzos del ermitaño y de su penitente, que ayunan y rezan de común acuerdo, tienen el mismo alcance narrativo que los de Salomón. Citemos al monje que acudió a arrepentirse ante un ermitaño: "mandóle que se enterrasse en una cueva e ayunasse tres semanas e rrogó por el deziendo. . ."19 Cada semana el ermitaño viene a preguntarle qué es lo que "ha visto" e interpreta la visión.

En consecuencia, vemos que la "revelación de valores verdaderos" da a entender uno o varios de los siguientes elementos: ermitaño, con frecuencia soledad en una caverna, ayuno, penitencia, visiones obtenidas a menudo en tres ocasiones, así como un pueblo de ascetas. Todos estos elementos, y con esta misma significación, se encuentran acumulados en el relato morisco. Podemos decir entonces que su problema esencial es el de la "verificación": ¿quién, de. tenta los verdaderos valores y cuáles son éstos?

Veamos de qué manera el relato morisco proporciona una respuesta a sus lectores cristianos y musulmanes.

Todos saben desde un principio que Pablo el judío se sitúa del lado "malo"; está dominado por su ambición, pues es un rey destructor; para engañar emplea el tema del rey que se hace ermitaño. No dice que lo sea, pero reúne todos los elementos necesarios para hacerlo creer, con una prudencia calculada en su primera salida, y con más audacia después. Falso revelador de valores, es, también "antidestinador" en un nivel pragmático, porque hace que los creyentes actúen en el sentido opuesto al que buscaban. Después de esta parte negativa, el texto nos muestra al "destinador" que lleva valores auténticos: el Corán, presente al final del texto, que califica de buena la actitud del Creyente y de los suyos.

La vida ejemplar de estos personajes piadosos, que viven retirados en cavernas, es lo que supuestamente convence a los cristianos. ¡Ellos son los verdaderos ermitaños! Es un llamado a la conversión de los cristianos, diciéndoles que Pablo es el único culpable, y que pueden vanagloriarse de sus orígenes ya que formaban parte, antes de su intervención, de ese misterioso pueblo virtuoso llamado a ser musulmán. Las alusiones a la comunidad nestoriana, jacobita y melquita nos llevan a un pasado preislámico donde todo era todavía posible.

Pero lo que prevalece es el elemento destinado a los musulmanes, que está en juego en todo el texto. Se emite un juicio muy claro

Libro de lo exenplos, núm. 122 (51), y Conde Lucanor, núm. 3. Un ángel revela a los ermitaños con quiénes estarán en el Paraíso, y los muestra de esa manera en dónde se encuentran los verdaderos valores.

${ }^{19}$ Libro de exenplos, núm. 23 y 106 (35). 
sobre el "iŷmā̄" ", consenso de la comunidad relativo a un punto de doctrina, cuestión muy controvertida desde época muy temprana. Este texto advierte a los musulmanes que es necesario rechazar esa práctica y no tolerar ningún cambio. Pablo propone simplemente examinar el tenor de su proposición, y vemos que el solo hecho de pensar que el cambio podría llegar a ser bueno conduce a los Creyentes a su perdición ${ }^{20}$.

Es obvio que este relato, aunque ofrece muchos puntos de contacto con la cultura cristiana, lo hace en un nivel tan mítico, que sería inadecuado para alcanzar su propósito conocido, que es el de refutar las palabras de los cristianos, y, por ende, de convencerlos.

Es el testigo de una situación conflictiva, en el que una comunidad resiste la asimilación, y afirma que es ella la que está calificada por Dios para ser la asimiladora. La fe religiosa ha sido para ella, por lo tanto, un factor de cohesión, de conciencia de su identidad y hasta fuente de actividad creadora en el terreno del relato ejemplar. En efecto, es la creencia en la inmutabilidad de la revelación lo que conduce a los moriscos a reivindicar no sólo a los santos personajes de la Biblia y los primeros cristianos, sino también a sus contemporáneos, quienes, según el texto, estaban llamados a ser musulmanes; de esta manera afirman su vitalidad y su fe en el porvenır.

Université Paul Valéry, Montpellier.

Denise Cardaillac

TRANSLITERACIÓN DE UN FRAGMENTO DE "PABLO Y LOS CREYENTES"

B. N. M., MS. 4944 , FOLS. $36 \mathrm{v}-42 \mathrm{R}$

Dize en-el-çinkeno libro de la-estori' a ke fizo Çayfu bnu 'Umar annabi (Allah cubhânahu lo-perdone), ke dixo Ibn 'Abbaç (apáguese Allah d-él) pirimo del-Annabi, ke clça ibnu Maryam estuvo en-lati ${ }^{y}$ erra santa ent ${ }^{c}$ re los Judiy os tanto komo el-K ri $^{y}$ ador kiso, pedirikándoles i kastigándolos, d-akí.ya ke Allah (cubhânahu) lo alęó a los çi elos. I 'a él ubireron seguido sakerrera d-akía unos seteçi entos onb res, i. ${ }^{y}$ staba en g $^{\mathrm{a}}$ ran porfidya kon los Judí ${ }^{y}$ os, kastigando $\mathrm{i}$ ped rikando kada di ‘a. Así ke se levantó Pablos el Judíy o, i ${ }^{y}$ era rey allí en akella ora, i p ${ }^{e}$ legó gà ran weste, i peleyó kon akellos $k^{e}$ reyentes/i desbaratólos, i sakólos de toda la-tiy erra santa, d-akí a los pu wertos. I no-los pudo matar a todos, así ke dixo: "Kompañí ${ }^{y}$ a:

\footnotetext{
${ }^{20}$ Las peripecias de la narración muestran un cambio en la situación, ya que el Creyente y los suyos rechazan la influencia de Pablo y huyen para encontrar la paz en las cavernas. La elección doctrinal sigue el mismo "trayecto": se admite en un principio cierto derecho a la evolución, que después es definitivamente rechazado, según el esquema de p. 183
} 
akello ke an dicho i dizen del-fecho de Almaçih es kosa ke bi' en aína $\mathrm{k}^{\mathrm{t}}$ reyerán las jentes, $\mathrm{i}$ tornarán kon-ellos. I kecçerán sobre nosotros, sakarnos an d-esta ti ${ }^{y}$ erra. Mas yo vos daré un konsejo, si me fez jura ke me seguiredes en ku al ki'ere kosa, seya bi'en o mal'. I dixí' eronle: "Palázenos". Así ke él dexó su-reismo, i fu"wese para ellos, i vestiy óse tales ropas komo ellos. I k ${ }^{w}$ ando pe legó a los puwertos do estaban los $\mathrm{k}^{\mathrm{e}}$ reyentes, tomáronlo / $\mathrm{i}$ dixi' éronle: "Bendicho seya el-Kri' ador, ke te aduxo a nuw esta ras manos". I díxoles: "Vengan vu ${ }^{w}$ est $^{\circ}$ ros mayores, ke yo-vos ki ero dezir por ké vín akí, ke no seríy a tan neçí ${ }^{y} o$ ni-tan-loko ke abí ${ }^{y}$ a a venir a ent ${ }^{\mathrm{a}}$ rar en $\mathrm{vu}^{\mathrm{w}} \mathrm{est}^{\circ}$ ro poder sin alguna razón". Así k-ellos ke reyéronselo, i vini y eron sus mayores, i dixiyéronle: “¿Ké dezíes?” I dixles: "Yo, ke depu wés ke yo torné de çaga de vosotros, yo enkont ${ }^{t}$ ré a 'lça Almaçih, i tiróme la-vista, i ${ }^{y}$ el seso, i.' el entendimi ${ }^{y}$ ento, i-y el oir. Así ke yo no oía, ni veía, ni emendi'a. I depu wés, tornéme, i dexóme sano así komo era de pirimero. I yo $\mathrm{p}^{\circ}$ rometí a $\mathrm{Di}^{y}$ os $\mathrm{ke}$ / yo seri ${ }^{y}$ a kon-vosotros, i ke ${ }^{e}$ reyerí $^{y} \mathrm{a}$ en vu ${ }^{w} \mathrm{est}^{\mathrm{a}}$. ra k'riyençi' $a$. Yo so venido akí por estar kon vosotros, i por most ${ }^{\mathrm{a}} \mathrm{rar}$ la ley a sus derechos". Así k-ellos k reyéronselo. I mandóles ke-l fizi' esen una kasa i ke le pusi' esen seniza sobre ke dormise, ke allí serviri' a ad Allah, i-" avezarlos ía I-attawrati. I fizi ${ }^{y}$ eron lo-ke les mandó, i-' avezábalos kada díy a. I depu ${ }^{w} e ́ s$, çerró la-pu ${ }^{\text {w }}$ erta i nosalli'ó a ellos, i'ubi ' eron g $^{\text {a }}$ ran reçelo ke no ubi yese visto kosa mala, i-' $a b^{i}$ ri $^{y}$ ó la-pu "erta a kabo de un di' 'a. I demandáronle ke por ké o por $\mathrm{ku}^{\mathrm{w}}$ al razón se çerro la pu ${ }^{\mathrm{w}}$ erta, o se abí' a visto kosa mala. / I dixo: "No-vi kosa nenguna mala, mas yo ob un aku" erdo, i dezirvos lo e, i se veredes ke sera bu weno, tomaldo; sino, tornadme d-ello". I díxoles: "¿Abedes visto kosa nenguna movida, sino de parte del-K 'ri' ador, ni sabe otro kabo, sino allí donde le mandaron?" I dixi yeron: "No". Dixo: " $\mathrm{Pu}$ "es yo e visto $\mathrm{k}$-ell-alba, $\mathrm{i}^{-y} \mathrm{el}$ sol, $\mathrm{i}$ la lûna, $\mathrm{i}$ las $\mathrm{p}^{\mathrm{a}}$ lanetas, $\mathrm{i}$ los signos, ke vi' enen del solano adelant. I no-vi'enen de akella part sino pork-es más razón k-enta-da akella part se debe fazer la oraçi'ón". I dixi'éronle: 'Dizes verdat'. I fizoles volver l-alqibla ke soli'an / seguir. Depu wés, çerró su pu werta, i-ubi yeron mayor mi ${ }^{\text {y }}$ edo ke no

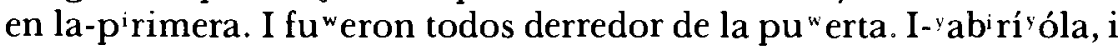
dixi 'éronle: "As visto alguno?" Dixo: "No. Mas e visto un akuwerdo". I dixi" éronle: "Dezid: veremos". I díxoles: “¿No dezides ke si

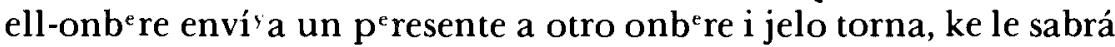
malo?" I dixi' éronle: "Dizes verdat". Dixo: "Puwes más onra debe

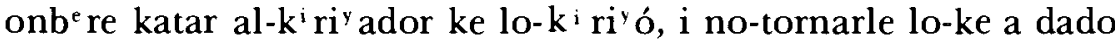
all-onb ${ }^{\mathrm{r}} \mathrm{re}$, ke sabedes muy bi'en ke $\mathrm{Di}^{y}$ 'os a dado todos los bi'enes de la-ti' erra i de los çi'elos por onrarvos, i komedes una kosa i bebedes otra. / I yo digo ke todas se deben komer, i todas son halâles", Dixi ' eron todos ke dezí' a g ${ }^{a}$ ran verdad, i komi ${ }^{y}$ eron todas las-kosas k-eran vedadas. I depu ${ }^{w}$ és, pasados $t^{\mathrm{e}}$ res di ${ }^{y}$ as, çerró la pu- ${ }^{\mathrm{w}}$ erta. $I^{-y}$ ubi $^{y}$ eron $\mathrm{mi}^{y}$ edo más ke las vezes $\mathrm{p}^{\mathrm{i}}$ rimeras. I $\mathrm{ku}^{\mathrm{w}}$ ando $\mathrm{sa}^{-}$ llí 'ó, dixi yeronle si avíy a visto algo. I dixo: "Lo ke yo e visto, no-lo- 
pu w edo dezir agora, d-akíy a ke salgan todos, saibo ku ${ }^{w}$ atro: el primero $\mathrm{Ya}^{\mathrm{c}}$ qûb, i Nastur, i Malquan, i-y el Mûmin". Así ke salliy eron todos, sino akellos $\mathrm{ku}^{\mathrm{w}}$ at ${ }^{\circ}$ ro. I díxoles: " $\mathrm{Pu}$ w es vosotros sabedes mâs, i sodes sabidores i mayores, kabdillos, ¿abedes supido ni visto / ni oído ke onb ${ }^{e}$ re karnal fese del-lodo fegura i vi ${ }^{y}$ a?" I dixi' eron: "No". I dixo: "¿Supi ${ }^{y}$ este ke onbe re karnal sanaba malawttos ni kont techos, ni reçuçitaba mu" ertos?" Dixi ${ }^{y}$ eron: "No". I díxoles muchas kosas d-akiya ke les dixo: "Yo digo k-este onbere "Içá k-es Allah. I se di'o a pareçer a nosotros, i despu"és s-enkubi ri ${ }^{y}$ ó". I díxoles muchas vanidades. I- ${ }^{y}$ el $p^{i}$ rimero ke $\mathrm{k}^{\mathrm{e}}$ reyó en-lo- ke Pawlos dixo era Yacqûb i Nas!ur, i ke dix k-era fijo de Diyos por vi ${ }^{y}$ a de $g^{a}$ raçi ${ }^{y} a$. I Malqûn dixo $k$-eran $t^{e}$ res segûn dizen agora estos goímes. I díxole el $\mathrm{k}^{y}$ re ente: / "Mentíç! Maldichos de Allah, no oyentes lo-ke vos dixo Allah i kastigó 'Içá! Ya-lo olvidastes, i pora Allah k-este maldicho no-vino akí sino por desfervos de la ley $i$ de la vu ${ }^{w} e^{2} t^{a}$ ra $k^{e}$ reyençi ${ }^{y}$ a. $I^{-y}$ ante $\mathrm{fu}^{w}$ emos nosotros konpañeros d-Almaçih, ke no este Kâfir, i lo viy emos i l-obedeçiy emos". I dexólos el-kreyente, i füwese a sus amigos i pariy entes $\mathrm{i}$ díxoles: "Ermanos, ¿no sabedes ke Almaçih k-era onb" re karnal, $i^{-y}$ era si ${ }^{y}$ ervo i mesajero del- $k^{i}$ ri $^{y}$ ador $i^{-y}$ asi vos lo-dixo?" I dixi eron: "Verdad dezíes". Dixo: "Pu" es sabed / k-este falso de Pawlos a engañado ad-akesta jente. I asi katad no-vos engañe a vos así komo los engañó". I tomó Pawlos i-yakellos ke lo-sigui'eron, i fuese para el Múmin i los k-eran kon-él para matarlos. I fuw eron a la-tierra de Axxâm i- ${ }^{y}$ enkativeronlos los Judi 'os. 1 dixi ${ }^{y}$ eronles todo el fecho, ke no an ido-s allí sino por salvarse, i ke no-keri' ${ }^{y}$ an parte d-este mundo sino "porke keremos morir en serviçi'o del k'riyador". I dixi' eron: "Dexadnos poblar la kuyebas i las ermitas semejante a la montañas". Así ke dexâronlos. I despu"ués, algunos de akellos / desk $^{e}$ re $^{y}$ entes ${ }^{i-y}{ }^{y} \tilde{n a d i}^{y}$ eron muchas kosas desordenadas, la-ku ${ }^{w} a l$ kosa dixo el Alqur'àn $k^{a}$ larament en una aȩçurata do dize:

"Warahbẩniyyatan ibtada ${ }^{\mathrm{e}}$ uha ma katabnaha calaihim illâ btighâda ridwàni llahi famâ $\mathrm{ra}^{c}$ auha haqqa ri làyatihà fa atainâ lladhina amanû ajruhum wa kathirun minhum façiqûna'. ki' ere dezir ke puso el $\mathrm{K}^{\mathrm{i}} \mathrm{ri}^{\mathrm{y}}$ ador en los korazones de akellos ke siguieron a "lça bnu Maryam ga $^{a}$ açi $^{y}$ la i misalikordi ${ }^{y}$ a i umillança, la kuwal se levantaron por sí $\mathrm{i}$ no les $\mathrm{fu}^{\mathrm{w}} \mathrm{e}$ mandado, mas fizi éronlo pora aver $\mathrm{g}^{\mathrm{a}}$ rado del- $\mathrm{K}^{\mathrm{i}} \mathrm{ri}^{\mathrm{y}}$ ador. I los $\mathrm{k}^{\mathrm{i}} \mathrm{ri}^{\dagger}$ entes dellos, darles-a su walardón (enti ${ }^{y}$ éndese el Mumin i los k-eran kon-él). I muchos de los otros rebeldes, ke no abrân walardón komo eran desk ${ }^{e}$ reídos. I desde k-estos alkançoron a nu $^{w}$ est $^{\circ}$ ro annabi Muhammad (salla llahu calaihi waçallama) t'renta onb $^{\mathrm{e}}$ res, $\mathrm{i} \mathrm{k}^{\mathrm{e}}$ reyeron su mesajeri ${ }^{y} \mathrm{a}$, i muri ${ }^{y}$ eron muçlimes. 
Valores señalados por el relato como FALSOS

Pablo es un falso portavoz; no obstante, su programa tiene éxito ante una parte del grupo.

Domilación de un hombre: INMANENCIA" (Pablo impone mediante la violencia o las artimañas sus propias decisiones)

\section{"EVOLUCIÓN"}

(El consenso de los creyentes autoriza:

Cambiar las prácticas

Divinidad de Jesús

Trinidad)
Valores señalados por el relato como VERDADEROS

El Corán es la voz verdadera; indica al final quién tiene razón.

Sumisión el Dios: "TRASCENDENCIA" (El creyente y los suyos dentro de las cavernas sirven a Dios como los ermitaños)

"INMUTABILIDAD"

Jesús, "hombre carnal" ante la transcendencia de Dios.

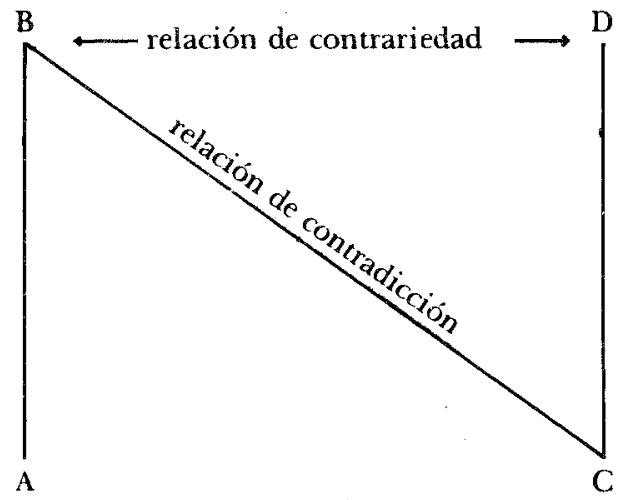

Pablo ha negado la "TRANSCENDENCIA"

(no se somete nunca a Dios)

Pablo ha negado la "INMUTABILIDAD"

(propone la posibilidad de aceptar

el "acuerdo" que ha tenido)
El Creyente y los suyos se niega a someterse a un hombre (Pablo) y huye. (Negación de la "INMANENCIA") Negación de la "EVOLUCIÓN" (El Creyente no admite la divinidad de Jesús, y eso le lleva a rechazar todos los "cambio" en conjunto)

Eso representa el "trayecto" recorrido mentalmente por el Creyente: en "A", no se diferencia de los demás; todos admiten la posibilidad de evolución por consenso de la comunidad propuesta por Pablo. En "B", se da cuenta que eso implicaba regirse por la voluntad del hombre y abandonar dogmas fundamentales para él. Entonces, en 'C", rechaza las proposiciones de Pablo y tiene que huir. En "D", el Enunciador del relato se vale del Corán para enaltecer los valores positivos propugnados por el Creyente. El mismo Corán añade que adoptar la vida de ermitaños no constituye un "cambio" es decir un acto de desobediencia, porque la sumisión del Creyente a Dios es perfecta. (Las palabras escritas en mayúsculas y entre comillas representan semas). 